\title{
JUSTICE AND DIGITALIZATION AS MUTUALLY DETERMINING FACTORS OF CRIMINAL - JURISDICTIONAL ACTIVITY DEVELOPMENT
}

\author{
Oleg A. Stepanov, Denis A. Pechegin, Mariia O. Dolova, Alexander A. Trefilov \\ The Institute of Legislation and Comparative Law \\ under the Government of the Russian Federation
}

\begin{abstract}
STEPANOV, O. A. et at. Justice and Digitalization as Mutually Determining Factors of Criminal-Jurisdictional Activity Development. Bratislava Law Review, Vol. 3, No. 2 (2019), pp. 60 - 68. ISSN 2585-7088, eISSN: 26446359
\end{abstract}

\begin{abstract}
The introduction of digital technologies has an impact on various aspects of criminaljurisdictional activity, optimizes the decision-making process based on data collection, coordination of actions of law enforcement officers, increases the effectiveness of their actions by minimizing the human factor in the process of legal decision-making through the use of the potential of artificial neural networks. On the basis of dialectical-materialist method and special legal research methods it is noted that the relationship between the concepts of "digital justice" and "justice" can be represented in the form of basic characteristics of the development of the same socially significant process, a key element of which is the use of robotic programs that simplify and accelerate human activities. It is pointed out that in the process of building in our society a fair legal basis of statehood, moral and legal culture as an integral attribute and a distinctive feature of the progressive development of the state is becoming increasingly important and of practical importance. The purpose of the article is to analyse the approaches and problems related to the Justice within the modern digital developments.
\end{abstract}

Key words: justice, digitalization, criminal law, procedure, criminal-jurisdictional activity.

\section{$1 \quad$ INTRODUCTION}

Order and justice, these universal values, along with law, determine the measure of freedom in our behaviour without prejudice to the interests and rights of those around us. ${ }^{1}$

Justice is the fundamental principle of "natural law", which belongs to man since birth. According to the French writer and philosopher Voltaire, even though nobody is born with clear notions of law and justice in mind, human dictates that at a certain age these truths come forth naturally.

The Roman lawyer Celsus believed that law was the science of good and justice. In concurrence with A.V. Saksonov's idea that it is not compulsoriness justice that defines the essence of law and builds basis for it, it should be noted that the ability of the law to express the idea of justice (law is

ADILOV, Z. A. The role of law enforcement agencies in providing a favorable socio-psychological climate in the process of crime prevention. In The modern scientist, № 5, 2017, p. $404-407$. 
statutory and materialized justice) is most closely associated with criminal and jurisdictional activity. A.F. Koni, famous Russian law scientist, had indicated that justice cannot be detached from law.

Being the result of the practical implementation of a certain part of state powers, which, together with the subjects of competence constitute the scope of competence of the executive and judicial powers, criminal jurisdictional activity is associated with the publication and application of criminal law and procedure.

At the same time, it is important to note that naturally religious principles are rooted in Russian criminal proceedings. For instance, the requirement of establishing the truth in criminal proceedings has been stipulated in the domestic legislation since pre-revolutionary times. Even though competitive trial proponents may point out that today the Criminal Code of Russia has not set forth any respective requirements, nevertheless numerous provisions indicate otherwise. It would suffice turning to the provisions of part 4, Art. 152; part 2, Art. 154; Art. 239.1 of the Russia's Criminal Procedure Code (Federal Law No. 174-FZ 18. 12. 2001) inter alia to find that, along with listing professional duties and regulations, these provisions guide law enforcement towards multifaceted, comprehensive, and objective review of case particularities.

Particular attention in this regard should be drawn to part 3 Art. 14 of the Russia's Criminal Procedure Code, which "... assumes that before recognizing any doubts irreparable, the court must try to eliminate them by all available means...”.

In addition, judicial practice focuses the judge on comprehensiveness, completeness, and objective approach to reviewing a case. For instance, a conviction by the court of first instance as per part 4 Art. 15 of the Russia's Criminal Procedure Code may be reversed if unjust. Existing experience in application of this norm testifies that it is applied to excessively severe (cruel) sentences, making a reference for law enforcement to the orthodox notions of mercy applicable to any person.

It should be noted that such origins of the law build basis for Russian law application process to be guided by its spirit, i.e. by justice, rather than by the book. ${ }^{2}$ After all, the phenomenon of law itself does not institute or define justice, but rather reflects it. The form, in which the law appears, on the one hand, and justice, on the other hand, may contradict each other in the process of unfair application of legal norms and in the issuance by public authorities of intrinsically unjust legal guidance. ${ }^{3}$ The proponents of natural law contemplated this phenomenon by stating that a formally legally sound law may harm justice.

\section{MATERIALS AND METHODS OF RESEARCH}

The theoretical basis of the study is created by papers of Russian and foreign researchers on the problems of criminal procedure in the development of information technologies (IT). Moreover, there are some major scientific works which are devoted to problems of use of the latest technologies in justice. For example, formation of conditions for "electronic justice" in the Russian Federation is subject of collective monograph "Justice in modern world".

2 AGARKOV, A.F. Criminological review of crimes within the street. In The modern scientist, № 5, 2017, p. 442 - 446.

3 KAMERGEROV, A.F. On some problems of increasing the legal culture of employees of law enforcement agencies. In The modern scientist, № 4, 2017, p. 209 - 213.

4 Justice in modern world, edited by V.M. LEBEDEV and T.Y. KHABRIEVA. M., 2012. 
There are a lot of international literature regarding to artificial intelligence ${ }^{5}$, for example: Holder C., Khurana V., Harrison F., Jacobs L. "Robotics and law: Key legal and regulatory implications of the robotics age"; "Robotics, AI and the Future of Law", Editors: Corrales M., Fenwick M., Forgó N. ${ }^{6}$

Despite the importance of such papers and monograph, the constant development of digital technologies and the development of legislation actualize the research of digitalization ${ }^{7}$ of criminal jurisdictional activity.

The methodological basis of the study is general scientific methods (system analysis, dialectical method, comparative method) and method of legal science (method of interpretation of legal norms).

As part of the general scientific methodology, a systematic approach allowed to comprehensively reveal the features of the introduction of digital technologies in the criminal procedure and identify some risks. Dialectical method of knowledge involves the study of any material or ideal object in the development and movement, taking into account the specific historical conditions of time and place. In every legal phenomenon, including criminal proceedings, it is possible to find the remains of the past, the basis of the present and the rudiments of the future. In this regard, the provisions of the Russias Criminal Procedure Code relating to the introduction of IT are a bridge between the current criminal process and the future of digitalized and informatized justice. Thus, the considered experience of informatization of modern criminal proceedings can be useful in the further improvement of Russian legislation and increase the efficiency of its application, as well as in scientific comparative legal research on this topic. ${ }^{8}$ Comparative method allowed comparing the trends, stages and results of digitalization of justice in Russia and in other countries. Method of interpretation of legal norms helps to understand the meaning and content of the rules and identify the will of the legislator.

\section{COURSE OF JUSTICE: “MODERN" VERSUS "TRADITION"}

The use of digital technologies that are currently capable of influencing various aspects of both public and criminal jurisdiction activities through optimization of the decision-making process based on data collection, coordination of law enforcement actions, raising efficiency of their actions and minimizing human error in the process of legal decision-making through the use of artificial neural networks may significantly reduce the chances for such contradictions. It should be noted, that artificial neural network is a type of machine learning loosely inspired by the structure of the human brain. A neural network is composed of simple processing nodes, or 'artificial neurons', which are connected to one another in layers. Each node will receive data from several nodes 'above' it, and give data to several nodes 'below' it. Nodes attach a 'weight' to the data they receive, and attribute a value to that data. If the data does not pass a certain threshold, it is not passed on to another node.

5 HOLDER C., KHURANA V., HARRISON F., JACOBS L. Robotics and law: Key legal and regulatory implications of the robotics age (Part I of II) // Computer law\&security review. 32 (2016), p. 383 - 402.

6 CORALlES M., FENWICK M., FORGO N. Robotics, AI and the Future of Law // Perspectives in Law, Business and Innovation, 2018.

7 KHABRIEVA, T. Law Facing the Challenges of Digital Reality. In Journal of Russian Law, № 9, 2018, p. 5 - 16; KHABRIEVA, T., CHERNOGOR, N. The Law in the Conditions of Digital Reality. In Journal of Russian Law, № 1, 2018, p. 85 - 102.

8 NAGOEVA, A.V. Systematism in the Criminal Legislation of the Russian Federation. In The Modern Scientist, № 1, 2018, p. 113-117; TAYLOVA, A.G., ADZIEVA, S.M. The role of the prosecutor's office in the formation of legal consciousness. In The modern scientist, № 7, 2017, p. $261-265$. 
The weights and thresholds of the nodes are adjusted when the algorithm is trained until similar data input results in consistent outputs. ${ }^{9}$

These networks are regarded as cognitive technologies where the machine performs work, which was previously considered the exclusive prerogative of humans as it uses its ability to simulate human mental activity and mimic the structure of the human nervous system. They can be self-learning and act on the basis of previous experience improving accuracy with time.

Still, such a self-learning system can track changes in the results of law enforcement activities, automatically assess the situation and send new relevant proposals that will improve criminal law and criminal procedure.

Moreover, in this case the technological nature of the law itself calls for no doubts as developed countries are taking long strides towards introducing elements of the so-called "electronic justice" while keeping in mind peculiarities of specific national justice system and the level of technological advancement. It is significant that on 4 December 2018 the European Commission on the efficiency of justice (CEPEJ) of the Council of Europe adopted the first European Ethical Charter on the Use of Artificial Intelligence in Judicial Systems and their environment, establishing ethical principles relating to the use of artificial intelligence (AI) in judicial systems, for example principle of respect for fundamental rights; principle of non-discrimination; principle of quality and security; principle of transparency, impartiality and fairness; principle "under user control". ${ }^{10}$

This shows that the potential of modern technologies and solutions will make it possible to implement the national model of digital justice in Russia in the foreseeable future, with the role of humans in deciding on a case minimized.

The term Digital Justice Model (Matrix) is well substantiated. Many recent legal studies have demonstrated increasingly frequent use of technical terms. The term Matrix has many meanings in various facets of human activity. But perhaps common to these definitions is the idea of the matrix as an image, a model, a projection.

The $10^{\text {th }}$ international legal forum of the Asia-Pacific countries held in September 2018 in Russia has proposed key highlights for transformation of national justice systems to envisage many legally significant actions committed in the virtual space. This means expanding the scope of legal regulations gaining multifaceted contents due to digitalization driving the expansion of the scope of rights as forecasting of justice becomes a new trend.

The purpose of such forecasting is to provide scientific foresight of the changes in legal conditions such as shifting goals and levels of legal regulation, designed to ensure the conversion of justice into law.

However, as the virtual space begins to engulf more and more legal relations, the formation of an environment that will allow making fair judicial decisions at the national level based on the use of neural network technologies (robots) gains growing importance. The law itself is a domain of rules, which can be presented through code interpretable via artificial reasoning. However, as Kevin D. Ashley has mentioned, features such as vagueness and the open-texture of statutory provisions need to be addressed to create accurate legal reasoning. ${ }^{11}$ This can be achieved by emulation of how courts

9 HOUSE OF LORDS. Select Committee on Artificial Intelligence Report of Session 2017-19, HL Paper 100, AI in the UK: ready, willing and able? p. 13.

10 European Ethical Charter on the Use of Artificial Intelligence in Judicial Systems and their environment was adopted at the 31st plenary meeting of the CEPEJ (Strasbourg, 3 - 4 December 2018).

11 KEVIN D. A. Artificial intelligence and legal analytics. Cambridge University Press, 2017, p. 3. 
provide their rulings: firstly, a theory based on previously existing cases is created; secondly, these created patterns are used to strengthen or weaken an argument; finally, example-based explanations illustrate why an argument can or cannot be applied. ${ }^{12}$

At the same time it should be understood how important the transparence and availability of a computer algorithm for making a legal decision. The study on topic of algorithmic decision systems (ADS), which has been written by Claude Castelluccia and Daniel Le Métayer, shows that algorithmic decision systems must meet a number of requirements, such as fairness, absence of bias or non-discrimination (for example the use of specific types of data such as ethnic origin, political opinions, gender, etc.). ${ }^{13}$

With this in mind, it is also important to note that the phrase "digital justice" is more in line with the future vector of development of the state and society, where the relationship between the concepts of "digital justice" and "justice" can be represented in the form of descriptors of the same process. As mentioned above, a key element of digital age justice will be the use of robot software that will facilitate and accelerate human activities, as well as artificial intelligence technologies, neural networks, through which the subjective role of man in decision-making as part of case reviews will be minimized.

As part of implementation of the Government program "Development of the Judicial System in Russia in 2013-2020", the Commission on the Use of Information Technologies to Improve the Quality of Life and Business Climate adopted on December 18, 2017, a roadmap towards integration of information available to various state bodies, building of a single information space encompassing the existing modular electronic platforms, and the use of digital technologies in decision-making.

Since the criminal process is a set of highly specific rules, standards and procedures governing the criminal proceedings, availability of necessary data enables prediction of specific outcomes of any action of a criminal proceedings participant.

This drives legislation towards allowing identification and authentication of subjects using any technically possible means, including electronic signature, biometric data, and personal number of an individual, all of which are designed to uniquely identify a person and establish his or her will to commit certain actions.

For instance, one of the latest draft laws developed by the Ministry of Justice of the Russian Federation provides the implementation into the work of the courts web conferencing, allowing the exchange of information between the court and other participants in real time without appearance in court. It is proposed to legislate the ability to remotely identify the participants of the procedure through their biometric data.

This circumstance brings forth technical simplification ${ }^{14}$ and improvement of citizens' access to justice through court websites and electronic forms of appeals and presentation of evidence and aims to develop a platform for the creation of robotic judges based on artificial intelligence technologies (AI). Artificial intelligence can be viewed as 'general' or 'narrow' in scope. Artificial general intelligence refers to a machine with broad cognitive abilities, which is able to think, or at least

12 This algorithm is proposed by Kevin D. Ashley. Ibid. p. $1-168$.

13 Understanding algorithmic decision-making: Opportunities and challenges, Study, Panel for the Future of Science and Technology. Brussels, 2019, p. 43 - 33.

14 WYSS, M. Öffentlichkeit von Gerichtsverfahren und Fernsehberichterstattung, Überlegungen zu einem grundrechtlichen Spannungsverhältniss unter besonderer Berücksichtigung der schweizerischen Rechtslage. In EuGRZ, № 23, 1996. 
simulate convincingly, all of the intellectual capacities of a human being, and potentially surpass them-it would essentially be intellectually indistinguishable from a human being. ${ }^{15}$

Robots or machines of this kind provide the most accurate predictions of outcomes for most cases reviewed in the European Court of Human Rights, where robot programs (machine programs) have access to evidence in a particular case, evaluate it in accordance with the specified parameters with the accuracy of the verdicts at the level of $79 \%$ in 584 reviewed cases. ${ }^{16}$

American researchers have developed dedicated "smart" software that was tasked to perform using dedicated algorithms a review of judicial decisions made by the Supreme Court of the United States during the period from 1816 to 2015 . This software identified a connection between the circumstances of cases and respective court rulings and accurately predicted the outcome of more than $70 \%$ of the 28,000 of the examined cases.

In France, the possibility of using robot software in justice was included in the agenda of reforming the national judicial system and the first stage it will cover more than 2.5 million cases.

In the most ambitious project to date, the Estonian Ministry of Justice has asked Estonia's chief data officer Ott Velsberg and his team to design a "robot judge" that could adjudicate small claims disputes of less than $€ 7,000$ (about $\$ 8,000$ ). Officials hope the system can clear a backlog of cases for judges and court clerks. The project is in its early phases and will likely start later this year with a pilot focusing on contract disputes. In concept, the two parties will upload documents and other relevant information, and the AI will issue a decision that can be appealed to a human judge. Many details are still to be worked out. ${ }^{17}$

Nevertheless, important is the fact that the robot judge cannot be bribed, it does not get tired or sick and it is designed to maximize the positive human potential in the field of justice.

Since the operation of such a system will take place within neural networks or other so-called "smart platforms" based on AI, lawyers in the foreseeable future are called upon to build virtual networks of rules for such platforms and robot judges, taking into account emerging practices, new legislation, relevant explanations of higher courts, as well as doctrinal changes, both at the national and international level. Thus, they will have to mostly prescribe the logic and order of behaviour for robot judges in the process of reviewing a particular case, to coordinate the activities of these robots.

In this fashion, the lawyers together with technologists and operators will act as co-developers of these systems focusing on generation of the fairest model of relations, based on the ideas of a famous digest of justice as unwavering and permanent will to give each his right. The use of such systems will significantly reduce the burden on judges and free up time for them to review more complex cases. The combined efforts of judges and "smart platforms" integrated into a single information space will increase the efficiency of justice at large bringing it to a new level.

In this regard, the Director for the Acceleration of Legal Technologies at Skolkovo Foundation said, in April 2018 that the Center of Competencies for the regulation of digital economy, which is founded as part of the Foundation, was developing draft terms of reference for a study to determine the possibility of translating the law into machine-readable form, automating their execution,

15 HOUSE OF LORDS. Op. cit. p. 15.

16 ALETRAS, N., TSARAPATSANIS, D., PREOŢIUC-PIETRO, D., LAMPOS, V. Predicting judicial decisions of the European Court of Human Rights: a Natural Language Processing perspective. In PeerJ Computer Science 2: e93, 2016.

17 NIILER, E. Can AI Be a Fair Judge in Court? Estonia Thinks So. [online]. Available at <https://www.wired.com/story/ can-ai-be-fair-judge-court-estonia-thinks-so/> [q. 2019-12-18]. 
developing a language and tools for describing self-executing contracts (an electronic algorithm focused on the fulfilment of obligations or monitoring their performance).

In the opinion of A. Ganser, legal expert from Dentons, artificial intelligence can be used to analyze the content of normative legal acts, to check their redundancy and consistency. "Machinereadable (semipalmata) provision is an algorithmic provision written in a programming language. Its main point is that it works automatically and always behaves the same with the same input data. Accordingly, variances in interpretation are not possible for those affected by self-executing rules as well as for those who control it"- Ganzer said.

However, as digital technologies are introduced, questions periodically arise about potential falsification of certain information during the investigation and trial of a criminal case. In case of bad faith of the investigator or judge it is necessary to exclude the possibility of making certain changes and additions to the electronic document both by prohibiting the modification of electronic information used in proving a criminal case, and by ensuring reliable protection of digital documents from possible modification. That's why it is important to make a scrupulous oversight and appropriate safeguards. It concerns not only the evidence but also the data on the basis of which artificial intelligence comes to conclusions. For example in Study on the human rights dimensions of automated data processing techniques and possible regulatory implications made by Council of Europe highlights that "depending on how crimes are recorded, which crimes are selected to be included within the analysis and which analytical tools are used, predictive algorithms may thus contribute to prejudicial decision-making and discriminatory outcomes". ${ }^{18}$

In this regard High-Level Expert Group on artificial intelligence set up by the European Commission formulated 33 concrete recommendations addressed to the European Institutions and Member States. These focus on four main areas where trustworthy artificial intelligence can help achieving a beneficial impact, starting with humans and society at large, and continuing then to focus on the private sector, the public sector and Europe's research and academia. ${ }^{19}$

\section{CONCLUSION}

In the process of building in our society a fair legal basis of statehood, moral and legal culture as an integral attribute and a distinctive feature of the progressive development of the state is becoming increasingly important and of practical importance. It opens huge ways to determine the truth as the main factor of justice. The relationship between the concepts of "digital justice" and "justice" can be represented in the form of basic characteristics of the development of the same socially significant process, a key element of which is the use of robot programs that simplify and accelerate human activities. It is really important for criminal jurisdictional activities to make it possible to find truth. The philosophy of ensuring a positive balance in terms of the introduction of the new technologies and the possible shortcomings of this process should be developed on the basis of minimizing the risk of electronic data substitution at the earliest. This will ensure that justice prevails in the sphere of criminal jurisdiction in Russia. The lawyers and law scientists are now able to decide whether the

18 Algorithms and human rights. Study on the human rights dimensions of automated data processing techniques and possible regulatory implications. DGI (2017) 12. p. 11.

19 Policy and investment recommendations for trustworthy Artificial Intelligence. High-Level Expert Group on Artificial Intelligence. European Commission. B-1049 Brussels. p. 47 - 49. 
digitalization in criminal justice becomes just new bright colour, modern talking, candy wrapper (form) or a big chance to provide our cultural sense and legal spirit in it.

With attention to possible risks about using AI, mentioned above, some de lege ferenda conclusions should be proposed. The field of digital justice (AI as a Tool for Social Justice) today requires a deep procedural rethinking on the basis of an interdisciplinary approach, detailed legislative regulation and consideration of constantly developing digital technologies. It is also necessary to develop a platform today for the creation of robotic judges. But at the initial stage of construction of the matrix of digital justice, the corresponding robots-programmes can contribute to the detection of crimes (Predicting Justice), and first of all those that are committed online. Thus, modern currency surrogates (cryptocurrencies) have long been a tool of the digital economy of various countries and can increase the rate of capital turnover in a given country, which has a positive effect on the economy. Anyway possibility for objection such decisions of robot judges should be granted for everyone to exclude any obstacles and wrongs.

\section{Bibliography:}

ADILOV, Z.A. The role of law enforcement agencies in providing a favorable socio-psychological climate in the process of crime prevention. In The modern scientist, № 5, 2017, p. 404 - 407.

AGARKOV, A.F. Criminological review of crimes within the street. In The modern scientist, № 5, 2017, p. $442-446$.

ALETRAS, N., TSARAPATSANIS, D., PREOŢIUC-PIETRO, D., LAMPOS, V. Predicting judicial decisions of the European Court of Human Rights: a Natural Language Processing perspective. In PeerJ Computer Science 2: e93, 2016.

Justice in modern world, edited by V.M. LEBEDEV and T.Y. KHABRIEVA. Moscow, 2012.

CORALLES M., FENWICK M., FORGO N. Robotics, AI and the Future of Law // Perspectives in Law, Business and Innovation. 2018.

HOLDER C., KHURANA V., HARRISON F., JACOBS L. Robotics and law: Key legal and regulatory implications of the robotics age (Part I of II) // Computer law \& security review. 32 (2016). p. $383-402$.

KAMERGEROV, A.F. On some problems of increasing the legal culture of employees of law enforcement agencies. In The modern scientist, № 4, 2017, p. $209-213$.

KEVIN D. ASHLEY Artificial intelligence and legal analytics. Cambridge University Press, 2017, p. 3.

KHABRIEVA, T. Law Facing the Challenges of Digital Reality. In Journal of Russian Law, № 9, 2018, p. 5 - 16.

KHABRIEVA, T., CHERNOGOR, N. The Law in the Conditions of Digital Reality. In Journal of Russian Law, № 1, 2018, p. 85 - 102.

NAGOEVA, A.V. Systematism in the Criminal Legislation of the Russian Federation. In The Modern Scientist, № 1, 2018, p. 113 - 117.

NIILER, E. Can AI Be a Fair Judge in Court? Estonia Thinks So. [online]. Available at <https://www.wired.com/story/ can-ai-be-fair-judge-court-estonia-thinks-so/> [q. 2019-12-18].

TAYLOVA, A.G., ADZIEVA, S.M. The role of the prosecutor's office in the formation of legal consciousness. In The modern scientist, № 7, 2017, p. 261 - 265.

WYSS, M., Öffentlichkeit von Gerichtsverfahren und Fernsehberichterstattung, Überlegungen zu einem grundrechtlichen Spannungsverhältniss unter besonderer Berücksichtigung der schweizerischen Rechtslage. In EuGRZ, № 23, 1996 . 


\section{Contact information:}

prof. Oleg A. Stepanov, Dr.

crim5@izak.ru

The Institute of legislation and comparative law under the government of the Russian Federation 117218, B. Cheremushkinskaya 34

\section{Moscow}

The Russian Federation

Denis A. Pechegin, Ph.D.

crim5@izak.ru

The Institute of legislation and comparative law under the government of the Russian Federation 117218 , B. Cheremushkinskaya 34

\section{Moscow}

The Russian Federation

Mariia O. Dolova, Ph.D.

crim5@izak.ru

The Institute of legislation and comparative law under the government of the Russian Federation 117218, B. Cheremushkinskaya 34

\section{Moscow}

The Russian Federation

Alexander A. Trefilov, Ph.D.

crim5@izak.ru

The Institute of legislation and comparative law under the government of the Russian Federation 117218 , B. Cheremushkinskaya 34

\section{Moscow}

The Russian Federation 